\title{
Single-Step Ladder Expansive Cranioplasty: 2-Year Follow-up
}

\author{
Sudip Kumar Sengupta ${ }^{1}$ Harish Bajaj ${ }^{1}$ Vinay Maurya ${ }^{1}$ \\ ${ }^{1}$ Department of Neurosurgery, Command Hospital (Eastern \\ Command), Kolkata, West Bengal, India \\ Address for correspondence Sudip Kumar Sengupta, MS, MCh, \\ 349/2, Dakshin Behala Road, Kolkata 700061, West Bengal, India \\ (e-mail: sudipdebashree@gmail.com).
}

Indian J Neurosurg 2021;10:263-265.

Decompressive hemicraniectomy is often resorted to in cases of severe head injury to deal with, and sometimes in anticipation of, a refractory raised intracranial pressure (ICP). With progressively reducing acceptable time interval between the primary surgery and cranioplasty, concerns regarding trephination syndrome and injury to the unprotected brain have substantially reduced. However, there still remains the necessity of bone flap preservation and a second surgery with its monetary and logistic implications that some patients can ill afford. With a view to devise a surgical technique that can accomplish the aim of achieving adequate intracranial volume expansion required to mitigate the raised ICP without having to subject the patient to a second surgery at a later date, "step ladder expansive cranioplasty" was conceptualized $^{1}$ and performed on a patient with acute subdural hematoma (SDH) and was published in Indian Journal of Neurosurgery as a technical note after 3 months of uneventful follow-up. ${ }^{2}$ We have subsequently followed up the patient for 2 years.

\section{Clinical Summary}

A 72-year-old man with multiple comorbidities was admitted with history of head injury with a Glasgow coma scale (GCS) score of $\mathrm{E}_{2} \mathrm{~V}_{2} \mathrm{M}_{5}$, in absence of any lateralizing signs. Noncontrast computed tomography (NCCT) of the head revealed an acute right-sided fronto-parieto-temporal SDH with a 10.2-mm midline shift and effacement of the basal cistern ( - Fig. 1A, B). The patient was taken up for a "single-step ladder cranioplasty," with written informed consent from the next of kin. The craniectomy defect in this patient was $12 \mathrm{~cm} \times 8 \mathrm{~cm}$ in size. The volume of dural outpouching in this patient, when measured from the craniectomy margin (using formula $2 / 3 \times$ surface area of the defect $\times$ height of the dural outpouching from the craniectomy defect) was $141.28 \mathrm{~cm}^{3}$. He was discharged from the hospital with a GCS of $\mathrm{E}_{4} \mathrm{M}_{6} \mathrm{~V}_{5}$ and without any focal neurologic deficit. Individual subsequently

published online

March 25, 2021
Dol https://doi.org/

$10.1055 / \mathrm{s}-0039-1697730$

ISSN 2277-954X. presented with generalized tonic-clonic seizures and was detected to have developed a chronic fronto-parieto-temporal SDH ( - Fig. 1C) requiring a single burr hole and drainage under local anesthesia. Subsequent recovery has been uneventful. Two years after surgery, he is comfortable with his obvious step deformity in the scalp ( -Fig. 2), not keen to undergo any corrective surgery for the same. NCCT of the head shows no feature of implant failure ( - Fig. 1D). There is a near-complete resolution of the cerebrospinal fluid (CSF) hygroma recorded in the NCCT of the head obtained on third week after surgery ( $\boldsymbol{- \text { Fig. }} \mathbf{1 E}$ ), and the brain appears to have expanded to occupy nearly the entire available space in the volume-augmented cranium ( - Fig. 1F).

\section{Discussion}

The maximum volume expansions achieved in this case was $141.28 \mathrm{~cm}^{3}$, as compared to the cases of unilateral decompressive hemicraniectomy recorded by Cavuşoğlu et al and Olivecrona et al to be of $102.7 \mathrm{~cm}^{3}$ and $109 \mathrm{~cm}^{3}$, respectively. Though the study by Münch et al recorded $157.6 \mathrm{~cm}^{3}$ as the maximum volume expansion achieved, the mean volume expansion reported was $92.6 \mathrm{~cm}^{3} .^{3-5}$

The volume-augmented cranium has an expanded surface area to cover and leaving any open wound or suture line under stress over a craniotomy would have disastrous consequences. Rotation scalp flap was successfully used to cover the defect.

\section{Conclusion}

Step ladder expansive cranioplasty offers a single-stage alternative that reinstates Monroe Kelley doctrine while achieving an assured intracranial volume augmentation that can be optimized based on our experience in the future. In patients uncomfortable with the cosmesis, taking down the construct at a later date will probably be easier than a routine
(C) 2021. Neurological Surgeons' Society of India.

This is an open access article published by Thieme under the terms of the Creative Commons Attribution-NonDerivative-NonCommercial-License, permitting copying and reproduction so long as the original work is given appropriate credit. Contents may not be used for commercial purposes, or adapted, remixed, transformed or built upon. (https://creativecommons.org/licenses/by-nc-nd/4.0/).

Thieme Medical and Scientific Publishers Pvt. Ltd. A-12, 2nd Floor, Sector 2, Noida-201301 UP, India 


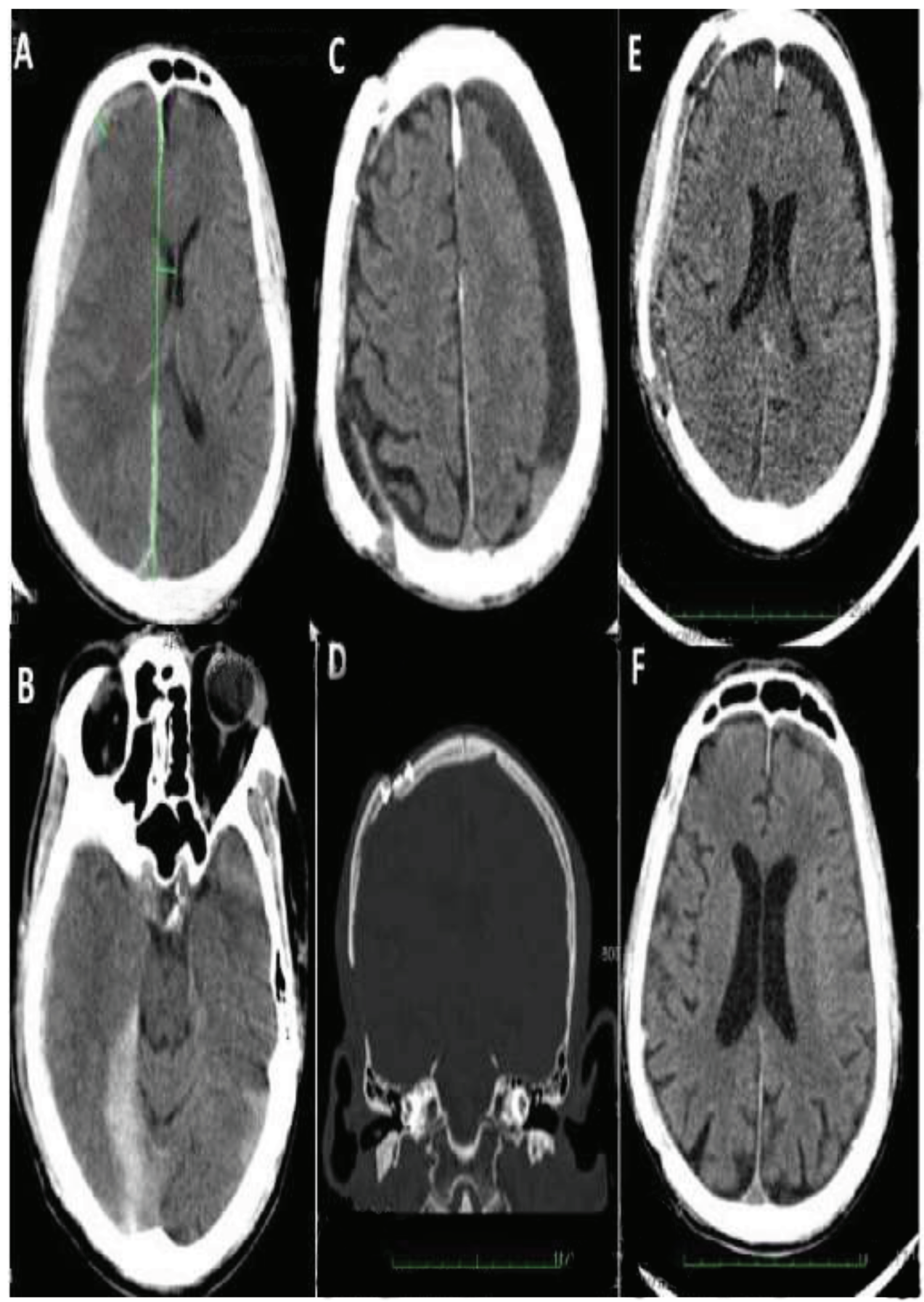

Fig. 1 Single-step ladder expansive cranioplasty: the index case. (A, B) Axial sections of preoperative NCCT scan image of head. (C) Contralateral chronic SDH with significant mass effect evident in 16 weeks postoperative NCCT image. (D) Intact cranioplasty construct 18 months after surgery showing step ladder expansion achieved by fixing the cranium and the bone flaps on two opposite surfaces of the titanium miniplates, thereby displacing the bone flap laterally from its preoperative position. (E) Contralateral CSF hygroma evident in 8 weeks postoperative NCCT of the head. (F) Eighteen months post surgery NCCT of the head. 


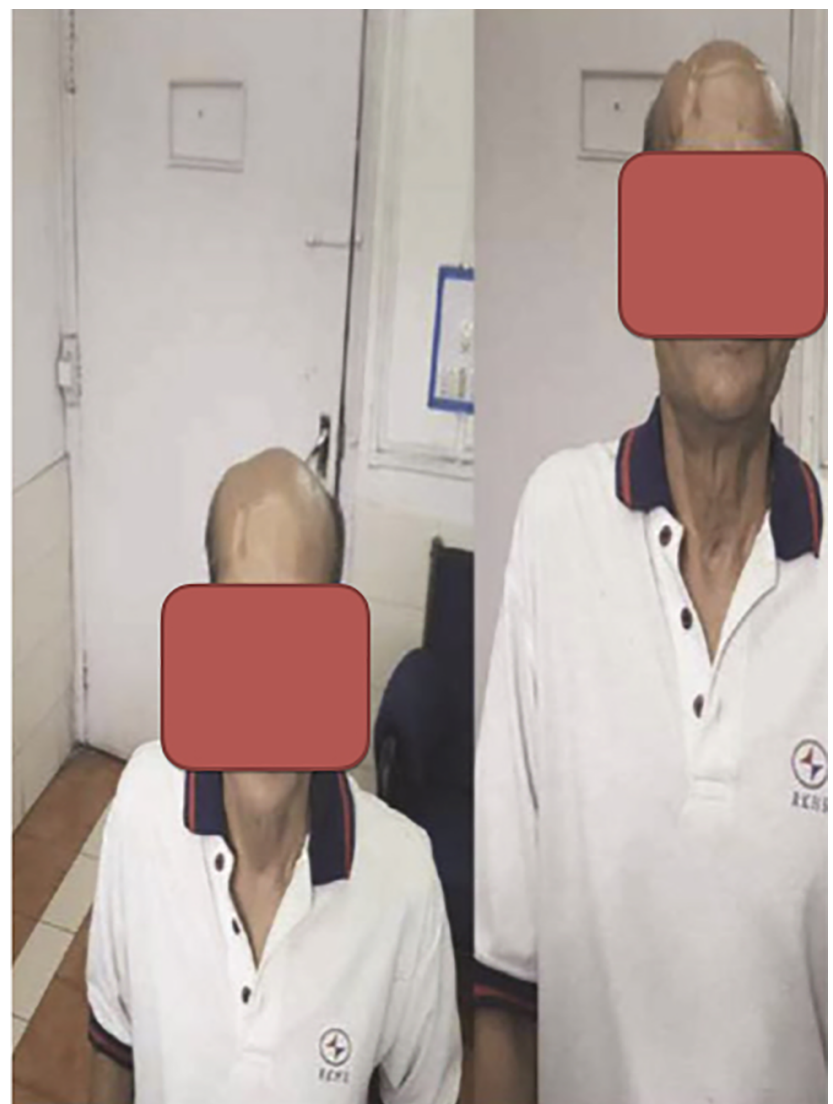

Fig. 2 Cosmesis: obvious step deformity. cranioplasty. Further clinical trial is required to see whether this case results are reproducible, once a consensus can be achieved on the volume expansion required to mitigate the raised ICP in different cases.

\section{Funding}

None.

Conflict of Interest

None declared.

\section{References}

1 Sengupta SK. Step-ladder expansive cranioplasty after decompressive craniotomy and expansive duraplasty: discussing possibilities on a mathematical model. Indian. J Neurosurg 2015;4(1):15-21

2 Sengupta SK. Single-step step ladder expansive cranioplasty. Indian. J Neurosurg. 2017;6(2):107-112

3 Münch E, Horn P, Schürer L, Piepgras A, Paul T, Schmiedek P. Management of severe traumatic brain injury by decompressive craniectomy. Neurosurgery 2000;47(2):315-322, discussion 322-323

4 Cavuşoğlu H, Kaya RA, Türkmenoğlu ON, Aydin Y. Value of early unilateral decompressive craniectomy in patients with severe traumatic brain injury. Ulus Travma Acil Cerrahi Derg 2010;16(2):119-124

5 Olivecrona M, Rodling-Wahlström M, Naredi S, Koskinen LO. Effective ICP reduction by decompressive craniectomy in patients with severe traumatic brain injury treated by an ICP-targeted therapy. J Neurotrauma 2007;24(6):927-935 